\title{
Phylogeography of Prunus Armeniaca L. By Chloroplast DNA and Nuclear Ribosomal Sequences
}

\section{Wen-Wen Li}

Xinjiang Agricultural University

\section{Li-Qiang Liu}

Xinjiang Agricultural University

\section{Qiu-Ping Zhang}

Liaoning Institute of Pomology

\section{Wei-Quan Zhou}

Xinjiang Agricultural University

\section{Guo-Quan Fan}

Xinjiang Academy of Agricultural Sciences

Kang Liao ( $D$ liaokang01@163.com )

Xinjiang Agricultural University

\section{Research Article}

Keywords: evolutionary history of organisms, P. armeniaca, AMOVA, phytogeography

Posted Date: February 22nd, 2021

DOI: https://doi.org/10.21203/rs.3.rs-215210/v1

License: (9) (i) This work is licensed under a Creative Commons Attribution 4.0 International License. Read Full License 


\section{Phylogeography of Prunus armeniaca L. by Chloroplast}

\section{DNA and Nuclear Ribosomal Sequences}

1 Wen-Wen Li', Li-Qiang Liu', Qiu-Ping Zhang², Wei-Quan Zhou', Guo-Quan

2 Fan $^{3}$, Kang Liao ${ }^{* \star 凶}$

$3 \quad{ }^{1}$ College of Horticulture and Forestry, Xinjiang Agricultural University, Urumqi, Xinjiang, 4 China. ${ }^{2}$ Xiongyue National Germplasm Resources Garden of the Liaoning Institute of 5 Pomology, Xiongyue, Shenyang, China. ${ }^{3}$ Luntai National Fruit Germplasm Resources 6 Garden of Xinjiang Academy of Agricultural Sciences, Luntai, Xinjiang, China. $\otimes_{\text {email: }}$ 7 liaokang01@163.com

\section{Abstract}

To clarify the phytogeography of Prunus armeniaca L., two chloroplast DNA fragments (trnL-trnF and $y c f 1)$ and the nuclear ribosomal DNA internal transcribed spacer (ITS) were employed to assess the genetic variation across $12 \mathrm{P}$. armeniaca populations. The results of cpDNA and ITS sequence data analysis showed that the level of genetic diversity in $P$. armeniaca was high (cpDNA: $H_{\mathrm{T}}=0.499$; ITS: $H_{\mathrm{T}}=0.876$ ), and the level of genetic differentiation was low (cpDNA: $F_{S T}=0.1628$; ITS: $F_{S T}=0.0297$ ). An analysis of molecular variance (AMOVA) revealed that most of the genetic variation in $P$. armeniaca occurred among individuals within populations. The value of interpopulation differentiation $\left(N_{S T}\right)$ was significantly higher than the number of substitution types $\left(G_{S T}\right)$, indicating a genealogical structure in $P$. armeniaca. $P$. armeniaca shared the same genotypes with related species and may be associated with them through continuous and extensive gene flow. The haplotypes/genotypes of cultivated apricot populations in Xinjiang, North China, and foreign apricot populations were mixed with large numbers of haplotypes/genotypes of wild apricot populations from the Ili River Valley. The wild apricot populations in the Ili River Valley contained the ancestral haplotypes/genotypes with the highest genetic diversity and were located in an area considered a potential glacial refugiume for P. armeniaca. Since population expansion occurred $16.53 \mathrm{kyr}$ ago, the area has provided a suitable climate for the population and protected the genetic diversity of $P$. armeniaca.

\section{Introduction}

The evolutionary history of organisms, including their genetic diversity, population structure and historical dynamics, is critical to species conservation ${ }^{1}$. Understanding the effects of climate change on the spatial genetic patterns of species, particularly endangered species, can help reveal not only the evolutionary history of species but also conservation strategies ${ }^{2-3}$. The origins of mountain biodiversity are complex and 
may include the immigration of preadapted lineages ${ }^{4-5}$, in situ diversification ${ }^{6}$, or the continuation of ancestral lineages ${ }^{7}$. Compared with those of other mountains, such as the Hengduan Mountains, the evolution and diversity of the Tianshan Mountains are still poorly understood. The Ili River Valley is located in the western part of the Tianshan Mountains in China and is surrounded by mountains on three sides. This valley was the main northern crossing of the ancient Silk Road. In the late Tertiary period, a large number of species, including wild apricot, wild apple and wild hawthorn, remained in the Ili River Valley and were important components of the deciduous broad-leaved forest at elevations below the coniferous forest and above the mountain grassland belt in the Xinjiang Uygur Autonomous Region, China ${ }^{8}$. However, there are few studies on the phylogeography of plant species in the arid region of Northwest China ${ }^{9-10}$.

In recent decades, the method of combining molecular data with paleoclimatic and geographical evidence has been effective in the study of system geography ${ }^{11-12}$. Many systematic geographic studies have shown that the Last Glacial Maximum (LGM) of the Pleistocene strongly influenced the genetic variation and biodiversity of plants throughout the Northern Hemisphere ${ }^{13-14}$. Especially during the Quaternary glacial period, species in the ice-free zone were mainly affected by the cold and dry climate ${ }^{15}$. Climatic fluctuations cause the distribution of species to shrink and expand ${ }^{16}$, and cold and dry climates prompted species to retreat to refugia, providing shelter for plants and animals ${ }^{17}$. As temperatures rose after the glacial period, species underwent population expansion, changes that left a genetic signature in their current populations 18. Although no unified glacial sheet had occurred in Asia, paleodata suggested that the distribution ranges of woody species in this region were similarly changed by the Quaternary climatic oscillations ${ }^{19}$. Based on the geographical distribution of genetic variation, the glacial refuges and postglacial revegetation routes of most woody plants are roughly consistent with fossil evidence ${ }^{20}$. However, due to the lack of fossil evidence, genetic evidence has become an important means of providing information on the distribution range of some woody species and the history of glacial refugia ${ }^{21-22}$. Volkova ${ }^{23}$ interpret the observed genetic structure [nuclear (ITS) and plastid DNA] of the Eurasian populations of Prunus padus as plausibly resulted from at least two cycles of glacial survivals in refugia followed by post-glacial colonization events. ${ }^{17}$ The complex geographic history may have provided a refuge for species from the last glacial period ${ }^{17}$. $\mathrm{Xu}$ et al. ${ }^{24}$ proposed that there were two possible independent glacial refugia in Northwest China: the Ili River Valley and the Northern Junggar Basin. Su et al. ${ }^{9}$ speculate that aggravation of the dry and cold climate during the early Quaternary, combined with plant physiological features, were determining factors contributing to the lineage split, and climate oscillations most likely led to the Yili range expansion. Therefore, it is of great interest to study the systematic geography of endemic plants in Northwest China against the background of Quaternary climatic fluctuations.

Apricot is a fruit of temperate and subtropical regions. Turkey, Uzbekistan, Iran, Algeria, Italy, Spain, China, Pakistan, France and Japan are the main producers of 
apricots (http://www.fao.org/home/zh). Apricot belongs to the section Armeniaca (Lam.) Koch, subgenus Prunophora Focke and genus Prunus (Rosaceae) ${ }^{25}$. Almost all cultivated apricots originated from $P$. armeniaca ${ }^{26}$. In China, wild apricot is distributed in the Ili River Valley (Tianshan Mountain area). The species is also distributed along the Tianshan mountains and westward to Kazakhstan, Kyrgyzstan and Uzbekistan. It is a relic of a broad-leaved forest from the late Tertiary period, which played a decisive role in the domestication of cultivated apricots worldwide ${ }^{27}$. As the world experienced extreme weather events, especially glacial periods, and most species went extinct, some of the more complex valleys may have become refugia for surviving forests and locally present species. As a result, traces of the species may be gradually shrinking in such areas. So, is Ili River Valley a glacial refugia for wild apricot?

Generally, seed dispersal distance is much less than that of pollen, and population divergence due to genetic drift will be more marked for chloroplast DNA (cpDNA) than for nuclear DNA. Indeed, cpDNA is considered to evolve very slowly, with low recombination and mutation rates ${ }^{28}$. Organelle markers could provide powerful tools for studying the phylogeography and migratory footprints of species ${ }^{29}$. Parental genetic markers are often combined with single-parent organelle markers for population genetics studies ${ }^{30}$. cpDNA and ITS sequence variations have been very effective in revealing the glacial refuges of plants ${ }^{29}$. cpDNA lineages usually show the unique geographical distribution and evolutionary history of natural populations and are therefore widely used in studies of systematic geography ${ }^{31}$. Li et al. ${ }^{32}$ successfully used cpDNA and ITS markers to evaluate the diversity and phylogenetic relationships among populations of Saxifraga sinomontana, indicating that the species had microrefugia during the Quaternary glacial period. In this study, we employed cpDNA (trnL-trnF and $y c f 1$ ) and nuclear ribosomal DNA (nrDNA) sequences to (1) reveal the haplotype/genotypic diversity and population genetic structure of the species; (2) test for potential glacial refugia for the species in the Ili River Valley; and (3) assess whether the refugia show signs of recent expansion.

\section{Materials and methods}

\section{Sample collection}

The samples used for cpDNA analysis included 123 individuals from 20 populations. A total of 171 individuals from 19 populations was used for the ITS analysis, of which 38 samples were obtained from the NCBI database (Table S1). The samples studied were from $P$. armeniaca and related species $(P$. sibirica, NAG; $P$. mandshurica, LX; P. dasycarpa, ZX; P. mume, ECG; Prunus zhengheensis, ZHX ${ }^{33}$; Prunus limeixing, LMX ${ }^{33}$ and Prunus brigantina, FGX). Prunus davidiana (T) was regarded as the outgroup.

Our collection of wild apricot ( $P$. armeniaca) populations covered most of the natural distribution in China, including Huocheng County (DZGhcmd, DZGhcy and DZGhcm populations), Yining County (DZGyn population), Gongliu County 
(DZGglb and DZGgld populations) and Xinyuan County (DZGxyt, DZGxya and DZGxyz populations). The distance between individuals sampled in each population was at least $100 \mathrm{~m}$. Young leaves were collected and dried immediately with silica gel.

The cultivated populations of $P$. armeniaca included the Xinjiang apricot group (CAG, cultivated apricots in Xinjiang), the North China apricot group (NCG, cultivated apricots in Shandong, Shaanxi, Gansu, Liaoning and Ningxia) and the foreign apricot group (EG, cultivated apricots in the USA, France, Italy and Australia). Detailed sample information was provided in Table 1 and Table S2. The main characteristics of different populations can be found in Zhang et al. ${ }^{8}$.

\section{DNA sequencing}

The total genomic DNA was extracted from the silica gel-dried leaf materials using a Plant Genomic DNA Kit (Tiangen Biotech, Beijing, China) ${ }^{34}$. The quality and concentration of the extracted DNA were determined by $1 \%$ agarose gel electrophoresis and ultraviolet spectrophotometry, respectively.

cpDNA and nrDNA sequences were initially screened from 15 samples using universal primers. The sequencing results showed that the sequences of cpDNA (trnL-trnF and $y c f 1$ ) and nrDNA (ITS) were polymorphic. cpDNA and ITS fragments were amplified by polymerase chain reaction (PCR), and the details of their primers are provided in Table S3 ${ }^{35-37}$. PCR was performed in a total volume of $25 \mu \mathrm{L}$ that contained $1 \mu \mathrm{L}$ DNA, $5.5 \mu \mathrm{L}$ PCR mix, $16.5 \mu \mathrm{L}$ double-distilled water and $1 \mu \mathrm{L}$ each forward or reverse primer. PCR amplifications were performed under the following conditions: $5 \mathrm{~min}$ of initial denaturation at $94^{\circ} \mathrm{C} ; 35$ cycles of $0.5 \mathrm{~min}$ at $94^{\circ} \mathrm{C}, 0.5$ min of annealing at $58^{\circ}$, and $0.5 \mathrm{~min}$ of extension at $72^{\circ} \mathrm{C}$, with $10 \mathrm{~min}$ of final extension at $72^{\circ} \mathrm{C}$. A CASpure PCR Purification Kit (CASarray, Shanghai, China) ${ }^{32}$ was used for purification. The purified PCR products were sequenced on an ABI PRISM 3730XL DNA Analyzer (Applied Biosystems, Foster City, CA, USA) ${ }^{38}$.

\section{Data analysis}

We used BioEdit ${ }^{39}$ to view and manually correct the sequencing results. We first used CLUSTAL $\mathrm{W}^{40}$ to align the sequences and coded indels following the method of Simmons and Ochoterena ${ }^{41}$. Then manual adjustments were made in MEGA ver. 7.0.26 ${ }^{42}$ to remove the overhanging tails to ensure a uniform sequence length. We concatenated two chloroplast fragments $(\operatorname{trn} \mathrm{L}-\operatorname{trn} \mathrm{F}$ and $y c f 1)$ to a separate matrix for subsequent analysis. We used DnaSP ver. 5.10 to identify different haplotypes (cpDNA sequences) or genotypes (ITS sequences). A haplotype network was constructed using TCS ver. 1.2.1 ${ }^{43}$. ArcGIS ver. 10.2 (http://desktop.arcgis.com) software was used to draw a haplotype geographical distribution map.

The haplotype/genotype diversity $(H d)$ and nucleotide diversity $(\pi)$ were calculated using DnaSP ver. 5.10 ${ }^{44}$ software. The within- population gene diversity $\left(H_{S}\right)$, gene diversity in all populations $\left(H_{T}\right)$, interpopulation differentiation $\left(G_{S T}\right)$ and 
number of substitution types $\left(N_{S T}\right)$ were calculated using PERMUT ver. $2.0{ }^{45}$. The last two indexes $\left(G_{S T}\right.$ and $\left.N_{S T}\right)$ were analyzed via permutation tests including 1,000 permutations. When $N_{S T}$ is greater than $G_{S T}$, it indicates the existence of genealogical geographic structure ${ }^{45}$. Analysis of molecular variance (AMOVA) was performed using Arlequin ver. 3.5.2.2 ${ }^{46}$ to partition the genetic variation at different levels, with statistical significance determined by 1,000 permutations.

To investigate the historical dynamics of $P$. armeniaca, mismatch distribution analysis was conducted using DnaSP ver. 5.10. The sum of squared deviations (SSDs), Harpending's raggedness index (HRI) ${ }^{45}$ and corresponding $P$ values were calculated using Arlequin ver. 3.5.2.2 ${ }^{46}$. Neutrality tests based on Tajima's $D$ and Fu's $F_{S}$ were conducted to detect departures from the population equilibrium by Arlequin ver. 3.5.2.2 ${ }^{46}$. According to the formula of Rogers and Harpending ${ }^{47}, \mathrm{~T}=\tau / 2 \mathrm{u}$, where " $\tau$ " is the parameter value from the mismatch distribution model. In the formula $u=\mu \mathrm{kg}$, " $\mu$ " is the base substitution rate (chloroplast angiosperms ${ }^{48}: 1.1 \times 10^{-9}$ ), " $\mathrm{k}$ " is the fragment length (cpDNA length after combination: 2,062 bp), and "g" is the generation time (20 years) ${ }^{49}$.

The outgroup was $P$. davidiana, and the time of peach-apricot differentiation was used as the calibration point ${ }^{50}$. The BEAUti interface was used to create an input file for BEAST ${ }^{51}$, to which the GTR $+\mathrm{I}+\mathrm{G}$ nucleotide substitution model. The data was analyzed using a relaxed log-normal clock model and a Yule Process speciation model for the tree priors. Prior settings for calibrating node were: offset of $55.1 \mathrm{Ma}$, a $\log$ mean of 1.0 ( $\log$ stdev of 0.5). The Bayesian Markov chain Monte Carlo simulation was run for 100 million generations with a sample frequency of 1,000, and the first $20 \%$ of generations were discarded as burn-in. Three independent analyses were conducted and combined by LogCombiner ver. 1.8.4. Finally, annotation and visualization of the maximum clade credibility tree were performed in TreeAnnotator 1.8.4 and FigTree ver. 1.4.3, respectively.

\section{Results}

\section{Haplotype/genotype phylogenetics and distribution}

Based on the concatenated cpDNA sequences (trnL-trnF and $y c f 1$ ), 33 haplotypes (H1-H33) were identified in 123 individuals from 20 populations of $P$. armeniaca and related species (Figure 1, Table 2). The alignment lengths of the two chloroplast fragments were $746 \mathrm{bp}$ and $1,316 \mathrm{bp}$, respectively, and the combined length was 2,026 bp. Variable sites among the 33 haplotypes are shown in Table S4. Species $P$. armeniaca harboured haplotype H1-H17 and H19-H20; species $P$. sibirica harboured haplotype $\mathrm{H} 28-\mathrm{H} 29$; species $P$. mandshurica harboured haplotype $\mathrm{H} 27$; species $P$. dasycarpa harboured haplotype $\mathrm{H} 33$; species $P$. mume harboured haplotype H20; species $P$. zhengheensis harboured haplotype H32; species $P$. limeixing harboured haplotype $\mathrm{H} 23-\mathrm{H} 26$; species $P$. brigantina harboured haplotype $\mathrm{H} 21-\mathrm{H} 22$; and species $P$. davidiana harboured haplotype $\mathrm{H} 30-\mathrm{H} 31$. The results showed that populations of different species did not share haplotypes. The results showed that, except for the EG 
accessions, the diversity of wild $P$. armeniaca (DZG accessions) (nucleotide diversity and haplotype diversity: $0.0013,0.444$, respectively) was higher than that of the CAG $(0.0006,0.239)$ and NCG $(0.0002,0.400)$ accessions.

In the ITS dataset, a total of 57 ITS genotypes were discovered in 171 individuals from 19 populations of $P$. armeniaca and its related species (Table 2, Figure S1), and the alignment length was $545 \mathrm{bp}$. The variable sites among the 57 genotypes are shown in Table S5. Species P. armeniaca harboured haplotype T1-T30, T42 and T48-T50; species $P$. sibirica harboured haplotype T2-T3, T8-T9, T12, T25 and T44-T47; species $P$. mandshurica harboured haplotype T3 and T9; species $P$. dasycarpa harboured haplotype $\mathrm{T} 2$ and T55-T57; species $P$. mume harboured haplotype T11 and T31-T41; species $P$. zhengheensis harboured haplotype T52-T54; species $P$. limeixing harboured haplotype $\mathrm{T} 3$ and $\mathrm{T} 43$; and species $P$. davidiana harboured haplotype T51. The results showed that, except for the EG accessions, the diversity of wild $P$. armeniaca (DZG accessions) (nucleotide diversity and haplotype diversity: $0.0055,0.878$, respectively) was higher than that of the CAG $(0.0053,0.832)$ and NCG $(0.0047,0.818)$ accessions.

Based on the concatenated cpDNA sequences (trnL-trnF and $y c f 1), 19$ haplotypes (G1-G19) were identified in 107 individuals from 12 populations of $P$. armeniaca (Figure 2). Variable sites among the 19 haplotypes are shown in Table S6. The $H d$ and $\pi$ values detected at the cpDNA sequence level in $P$. armeniaca were 0.548 and $1.9 \times 10^{-3}$, respectively. The geographic distribution of the 19 haplotypes is shown in Figure 2A, showing that G1 haplotypes were distributed in all populations. The cpDNA haplotype network (Figure 2B) showed that 7 haplotypes were differentiated from haplotype G1 by a one-step mutation with G1 at the center. Three haplotypes were differentiated from G11 by a one-step mutation. The overall network map showed a "star-like" distribution pattern. Based on the ITS sequences, 34 haplotypes (P1-P34) were identified in 124 individuals from 12 populations of $P$. armeniaca (Figure S2). The $H d$ and $\pi$ values detected at the ITS sequence level in $P$. armeniaca were 0.865 and $5.4 \times 10^{-3}$, respectively.

\section{Population structure and genealogical geography}

In $P$. armeniaca, the gene diversity in all populations (cpDNA: $H_{\mathrm{T}}=0.499$; ITS: $H_{\mathrm{T}}=0.876$ ) was higher than that within populations (cpDNA: $H_{\mathrm{S}}=0.490$; ITS: $H_{\mathrm{S}}=0.0 .794$ ) (Table 3 ). A permutation test showed that $N_{\mathrm{ST}}$ was significantly higher than $G_{\mathrm{ST}}$ (cpDNA: $N_{\mathrm{ST}}=0.227>G_{\mathrm{ST}}=0.020 ;$ ITS: $N_{\mathrm{ST}}=0.126>G_{\mathrm{ST}}=0.094 ; \quad P<0.05$ ), indicating that $P$. armeniaca has a significant geographical structure (Table 3).

AMOVA revealed significant genetic differentiation among all populations of $P$. armeniaca (cpDNA: $F_{S T}=0.1628, P<0.001$; ITS: $F_{S T}=0.0297, P<0.001$ ), with most of the genetic diversity occurring within the populations and relatively little occurring among them (Table 4).

Demographic history and estimation of divergence times 
The mismatch distribution based on cpDNA and ITS dataset analysis, in which multimodal data were drawn from the cultivated populations or all populations, indicated a demographic equilibrium (Figure 3, Figure S3). Both the neutrality tests based on Tajima's $D$ (cpDNA: $-2.272, P<0.05$; ITS: $-0.966, P<0.05$ ) and Fu's $F_{S}$ (cpDNA: $-5.8253, P<0.05$; ITS: $-12.223, P<0.05$ ) and the mismatch distribution analysis (Figure 3 ) based on the cpDNA and ITS dataset suggested recent range or demographic expansion in wild populations of $P$. armeniaca. In addition, neither the SSDs (cpDNA: $0.037, P>0.05$; ITS: $0.002, P>0.05$ ) nor the HRI (cpDNA: 0.179 , $P>0.05$; ITS: $0.017, P>0.05$ ) showed significant positive values (Table 5), indicating no deviation of the observed mismatch distribution from that obtained via model simulation under sudden demographic expansion. Thus, we concluded that the demographic expansion time of the wild populations of $P$. armeniaca was $16.53 \mathrm{kyr}$ ago.

The cpDNA dataset was employed to estimate the time of the onset of divergence between $P$. armeniaca and its related species (Figure 4, Table S7). The results showed that 33 haplotypes were divided into two groups: $P$. armeniaca (blue) and related species (green) (Figure 4). The divergence time revealed that the differentiation of $P$. armeniaca from its related species occurred during the middle Eocene, at approximately $45.68 \mathrm{Ma}(95 \% \mathrm{HPD}=28.47-61.87)$. The onset of intraspecific divergence in $P$. armeniaca was estimated to be 25.55 (95\% HPD $=12.93-39.63)$ Ma.

\section{Discussion}

Based on the cpDNA sequences, the total genetic diversity in $P$. armeniaca was relatively low but sufficient to reflect the long evolutionary history and wide distribution of the species ${ }^{49}$. Many scholars ${ }^{52-55}$ believed that the diversity of wild apricot was richest in the Ili River Valley, with low levels of genetic differentiation and genetic variation mainly occurring within populations. Hu et al. ${ }^{54}$ used simple sequence repeat markers to analyze the diversity of 212 apricot germplasm from 14 populations in Ili River Valley. Among them, the Tuergen township in Xinyuan County had the highest genetic diversity, and the genetic distance between populations was significantly correlated with the geographical distance. The self-incompatible pattern, wide distribution, long-distance transmission of pollen through insects and strong winds are the main factors affecting the genetic variation structure ${ }^{54}$. The haplotype/genotypic diversity of the wild populations of $P$. armeniaca in the Ili River Valley obtained from cpDNA and ITS data was relatively high (Table 2). The results of AMOVA (Table 4) showed that the genetic diversity in P. armeniaca mainly occurs within populations (cpDNA: $83.72 \%$; ITS: 97.03\%), but there were also significant differences among populations (cpDNA: 16.28\%; ITS: $2.97 \%$ ), which was consistent with previous results based on simple repeat markers ${ }^{54}$. The relatively high genetic diversity also confirmed the status of Tianshan wild apricot as the origin center of cultivated apricot ${ }^{54}$. The limited informative mutation sites among ITS genotypes led to an almost complete lack of resolution for the construction of genotype relationships (Figure S2), suggesting rapid intraspecific 
differentiation in the most recent species of $P$. armeniaca, and similar results were found in Saxifraga sinomontana ${ }^{32}$.

The genetic backgrounds of the NAG, LX, and ZX populations had the same genotypes (T2, T7-8 and T12) as P. armeniaca, indicating that they are associated with $P$. armeniaca through continuous and extensive gene flows ${ }^{56}$. Based on microsatellite markers, Liu et al. ${ }^{56}$ believed that $P$. sibirica was divided into two groups, one of which may have under gene exchange with $P$. armeniaca, further verifying our results. In addition, the authors found an extensively mixed genetic background in the germplasm of cultivated apricots in China. This study indicated that the cultivated and wild populations of $P$. armeniaca had the same ancestral haplotype, which was G1. The haplotypes of the CAG, EG and NCG populations were mixed with the haplotypes/genotypes of the large wild populations ( $P$. armeniaca). According to coalescent theory ${ }^{57}$, chloroplast haplotype $\mathrm{G} 1$, which was widely distributed and located in the center of the chloroplast network (Figure 2), should be considered the oldest haplotype. The Kashgar, Hotan and Aksu oasis areas around the Tarim Basin in the southern part of the Xinjiang Uygur Autonomous Region of China are the main apricot-producing areas and contain the greatest abundance of apricot cultivars. There is only one mountain between southern Xinjiang and the Ili Valley, and there are several corridors between the northern and southern Tianshan Mountains. Therefore, the apricots cultivated in Xinjiang, southern Tianshan Mountains (CAG), most likely evolved from the spread of wild apricots in the Ili River Valley.

Liu et al. ${ }^{56}$ believed that apricots have experienced at least three domestication events, which formed apricots in Europe (the United States and continental Europe), southern Central Asia (Turkmenistan, Afghanistan, India) and China, respectively, in which both ancient gene flows and recent gene mixing phenomena exist. Central Asia was the most diverse center of wild apricots, with genetically differentiated populations that may have resulted from population isolation in glacial shelters ${ }^{56}$. In this study, the nucleotide diversity and haplotype/genotype diversity of wild apricots (DZG accessions) were higher than that of CAG and NCG accessions. These findings are reasonable from a historical perspective, as there was extensive cultural contact along the Silk Road from 207 BCE to $220 \mathrm{CE}^{58}$. Therefore, historical and commercial influences may have contributed to the development of this unique species of cultivated apricot.

The theory and method of phylogeography can reveal the historical dynamics of species or populations, such as expansion, differentiation, isolation, migration and extinction ${ }^{29}$. Phylogeographic studies have shown that ancient haplotypes and high genetic diversity can be used to identify refuges ${ }^{1,59}$. Many scholars $17,19,24$ have suggested that the complex geographic history of Northwest China may have provided refuges for species during glacial periods. By combining two markers, we showed that the wild populations distributed in the Ili River Valley all contained ancestral haplotypes/genotypes and had high genetic diversity (Table 2). These populations were located in areas considered glacial refugia for $P$. armeniaca, which 
appears to be a relic of Quaternary glaciation. The region provides a suitable climate for the biological community and protects the genetic diversity of $P$. armeniaca. Both neutrality tests and mismatch distribution analysis based on the cpDNA and ITS dataset suggested recent range or demographic expansion of wild populations of $P$. armeniaca. We estimated that the recent demographic expansion time of the wild populations of $P$. armeniaca was $16.53 \mathrm{kyr}$ ago, that is, at the end of the LGM ${ }^{49}$.

The taxa-sampling and the fossil calibration strategy will influence the age estimation ${ }^{60-61}$. Due to the lack of fossil evidence of $P$. armeniaca, we used the peach-apricot divergence time as the calibration point. In this study, we tried to use cpDNA data set to construct the divergence time, and the effect was relatively ideal. However, compared with the median ages estimated by Chin et al. ${ }^{50}$ (mean age of 31.1 Ma), the divergence time estimates in this study should be treated with caution, because the limited coverage and a low number of calibration points may skew divergence time estimation of $P$. sibirica (mean age of $33.43 \mathrm{Ma}$ ) too high.

\section{Conclusion}

Based on the cpDNA and ITS datasets, the genetic diversity of $P$. armeniaca remains high. Haplotypes/genotypes shared with close relatives tend to occur in geographically similar populations, and $P$. armeniaca exhibits a genealogical structure. The haplotypes/genotypes of cultivated apricot populations in Xinjiang, North China, and foreign apricot populations were mixed with large numbers of haplotypes/genotypes of wild apricot populations from the Ili River Valley. We argue that P. armeniaca originated in Northwest China (Ili Valley). Affected by the Quaternary glaciation of the Pleistocene, the Ili River Valley in Northwest China served as a glacial refugium for $P$. armeniaca, providing the species with a suitable climate and preserving its genetic diversity. During the interglacial period, the species underwent a recent expansion in the face of favorable climatic and environmental conditions. Apricots originated during the middle Eocene, and the cultivated apricot in Xinjiang originated from the Ili River Valley in Northwest China.

\section{References}

1. Meng, H. H. \& Zhang, M. L. Diversification of plant species in arid Northwest China: species-level phylogeographical history of Lagochilus Bunge ex Bentham (Lamiaceae). Mol. $\quad$ Phylogenet. $\quad$ Evol. https://doi.org/10.1111/jse.12088 (2015).

2. Pennington, R. T. et al. Contrasting plant diversification histories within the Andean biodiversity hotspot. Proc. N. Acad. of Sci. USA 107, 13783-13787. https://doi.org/10.1073/pnas.1001317107 (2010).

3. Hughes, C. \& Eastwood, R. Island radiation on a continental scale: Exceptional rates of plant diversification after uplift of the Andes. Proc. N. Acad. of Sci. USA 103, 10334-10339. https://doi.org/10.1073/pnas.0601928103 (2006).

4. Johansson, U. S. et al. Build-up of the Himalayan avifauna through immigration: 
a biogeographical analysis of the Phylloscopus and Seicercus warblers. Evolution 61, 324-333. https://doi.org/10.1111/j.1558-5646.2007.00024.x (2007).

5. Hughes, C. E. \& Atchison, G. W. The ubiquity of alpine plant radiations: from the Andes to the Hengduan Mountains. New Phytol. 207, 275-282. https://doi.org/10.1111/nph.13230 (2015).

6. Lagomarsino, L. P., Condamine, F. L., Antonelli, A., Mulch, A. \& Davis, C. C. The abiotic and biotic drivers of rapid diversification in Andean bellflowers (Campanulaceae). New Phytol. 210, 1430-1442. https://doi.org/10.1111/nph.13920 (2016).

7. Ebersbach, J. et al. In and out of the Qinghai-Tibet Plateau: divergence time estimation and historical biogeography of the large arctic-alpine genus Saxifraga L. J. Biogeogr. 44, 900-910. https://doi.org/10.1111/jbi.12899 (2017).

8. Zhang, J. Y. \& Zhang, Z. Flora of Chinese Fruit Trees 61-62 (China forestry press, 2003)

9. Su, Z., Zhang, M. \& Sanderson, S. C. Chloroplast phylogeography of Helianthemum songaricum (Cistaceae) from northwestern China: implications for preservation of genetic diversity. Conserv. Genet. 12, 1525-1537. https://doi.org/10.1007/s10592-011-0250-9 (2011).

10. Xie, K. Q. \& Zhang, M. L. The effect of Quaternary climatic oscillations on Ribes meyeri (Saxifragaceae) in northwestern China. Biochem. Syst. Ecol. 50, 39-47. https://doi.org/10.1016/j.bse.2013.03.031 (2013).

11. Salvi, D., Schembri, P., Sciberras, A. \& Harris, D. Evolutionary history of the Maltese wall lizard Podarcis filfolensis: insights on the 'Expansion-Contraction' model of Pleistocene biogeography. Mol. Ecol. 23, 1167-1187. https://doi.org/10.1111/mec.12668 (2014).

12. Liu, J. Q., Sun, Y. S., Ge, X. J., Gao, L. M. \& Qiu, Y. X. Phylogeographic studies of plants in China: Advances in the past and directions in the future. J. Syst. Evol. 50, 267-275. https://doi.org/10.1111/j.1759-6831.2012.00214.x (2012).

13. Hewitt, G. The genetic legacy of the Quaternary ice ages. Nature 405, 907-913. https://doi.org/10.1038/35016000 (2000).

14. Hewitt, G. M. The structure of biodiversity-insights from molecular phylogeography. Front. Zool. 1, 1-16. https://doi.org/10.1186/1742-9994-1-4 (2004).

15. Willis, K. J. \& Niklas, K. J. The role of Quaternary environmental change in plant macroevolution: the exception or the rule? Philos. Trans. R. Soc. Lond. B 359, 159-172. https://doi.org/10.1098/rstb.2003.1387 (2004).

16. Schmitt, T. Molecular biogeography of Europe: Pleistocene cycles and postglacial trends. Front. Zool. 4, 11. https://doi.org/10.1186/1742-9994-4-11 (2007).

17. Shen, L., Chen, X. Y. \& Li, Y. Y. Glacial refugia and postglacial recolonization patterns of organisms. Acta Ecol. Sin. 22, 1983-1990. https://doi.org/10.1088/1009-1963/11/5/313 (2002).

18. Schonswetter, P., Popp, M. \& Brochmann, C. Rare arctic-alpine plants of the 
European Alps have different immigration histories: the snow bed species Minuartia biflora and Ranunculus pygmaeus. Mol. Ecol. 15, 709-720. https://doi.org/10.1111/j.1365-294X.2006.02821.x (2006).

19. Guo, Y. P., Zhang, R., Chen, C. Y., Zhou, D. W. \& Liu, J. Q. Allopatric divergence and regional range expansion of Juniperus sabina in China. J. Syst. Evol. 48, 153-160. https://doi.org/10.1111/j.1759-6831.2010.00073.x (2010).

20. Jaramillo-Correa, J. P., Beaulieu, J. \& Bousquet, J. Variation in mitochondrial DNA reveals multiple distant glacial refugia in black spruce (Picea mariana), a transcontinental North American conifer. Mol. Ecol. 13, 2735-2747. https://doi.org/10.1111/j.1365-294X.2004.02258.x (2004).

21. Afzal-Rafii, Z. \& Dodd, R. S. Chloroplast DNA supports a hypothesis of glacial refugia over postglacial recolonization in disjunct populations of black pine (Pinus nigra) in western Europe. Mol. Ecol. 16, 723-736. https://doi.org/10.1111/j.1365-294X.2006.03183.x (2007).

22. Anderson, L., Hu, F., Nelson, D., Petit, R. \& Paige, K. Ice-age endurance: DNA evidence of a white spruce refugium in Alaska. Proc. N. Acad. of Sci. USA 103, 12447-12450. https://doi.org/10.1073/pnas.0605310103 (2006).

23. Volkova, P. A., Burlakov, Y. A. \& Schanzer, I. A. Genetic variability of Prunus padus (Rosaceae) elaborates "a new Eurasian phylogeographical paradigm". Plant Syst. Evol. 306, 1-9. https://doi.org/10.1007/s00606-020-01644-0 (2020).

24. Xu, Z. \& Zhang, M. L. Phylogeography of the arid shrub Atraphaxis frutescens (Polygonaceae) in northwestern China: evidence from cpDNA sequences. $J$. Hered. 106, 184-195. https://doi.org/10.1093/jhered/esu078 (2015).

25. Rehder, A. Manual of cultivated trees and shrubs hardy in North America, exclusive of the subtropical and warmer temperate regions 345-346 (Macmillan, 1927)

26. Zhebentyayeva, T. N., Ledbetter, C., Burgos, L., \& Llácer, G. Fruit breeding 415-458 (Springer, 2012)

27. Zhebentyayeva, T. N., Reighard, G. L., Gorina, V. M. \& Abbott, A. G. Simple sequence repeat (SSR) analysis for assessment of genetic variability in apricot germplasm. Theor. Appl. Genet. 106, 435-444. https://doi.org/10.1007/s00122-002-1069-z (2003).

28. Schaal, B. A., Hayworth, D. A., Olsen, K. M., Rauscher, J. T. \& Smith, W. A. Phylogeographic studies in plants: problems and prospects. Mol. Ecol. 7, 465-474. https://doi.org/10.1046/j.1365-294x.1998.00318.x (1998).

29. Avise, J. C. Phylogeography: retrospect and prospect. J. Biogeogr. 36, 3-15. https://doi.org/10.1111/j.1365-2699.2008.02032.x (2009).

30. Poudel, R. C., Möller, M., Li, D. Z., Shah, A. \& Gao, L. M. Genetic diversity, demographical history and conservation aspects of the endangered yew tree Taxus contorta (syn. Taxus fuana) in Pakistan. Tree Genet. Genom. 10, 653-665. https://doi.org/10.1007/s11295-014-0711-7 (2014).

31. Dutech, C., Maggia, L. \& Joly, H. Chloroplast diversity in Vouacapoua americana (Caesalpiniaceae), a neotropical forest tree. Mol. Ecol. 9, 1427-1432. 
https://doi.org/10.1046/j.1365-294x.2000.01027.x (2000).

32. Li, Y. et al. Rapid intraspecific diversification of the Alpine species Saxifraga sinomontana (Saxifragaceae) in the Qinghai-Tibetan Plateau and Himalayas. Front. Genet. 9, 381. https://doi.org/10.3389/fgene.2018.00381 (2018).

33. Zhang, Q. P. \& Liu, W. S. Advances of the apricot resources collection, evaluation and germplasm enhancement. Acta Hortic. Sin. 45, 1642-1660. https://doi.org/10.16420/j.issn.0513-353x.2017-0654 (2018).

34. Hu, Z. B. et al. Population genomics of pearl millet (Pennisetum glaucum (L.) R. Br.): Comparative analysis of global accessions and Senegalese landraces. BMC Genomics 16, 1048. https://doi.org/10.1186/s12864-015-2255-0 (2015).

35. White, T. J., Bruns, T., Lee, S. \& Taylor, J. Amplification and direct sequencing of fungal ribosomal RNA genes for phylogenetics. PCR Protoc.: Guide Methods Appl. 18, 315-322. (1990).

36. Dong, W. et al. ycf1, the most promising plastid DNA barcode of land plants. Sci. Rep. 5, 8348. https://doi.org/10.1038/srep08348 (2015).

37. Bortiri, E. et al. Phylogeny and Systematics of Prunus (Rosaceae) as Determined by Sequence Analysis of ITS and the Chloroplast $t r n \mathrm{~L}-\operatorname{trnF}$ Spacer DNA. Syst. Bot. 26, 797-807. https://doi.org/full/10.1043/0363-6445-26.4.797 (2001).

38. Zhang, Q. Y. et al. Latitudinal Adaptation and Genetic Insights Into the Origins of Cannabis sativa L. Front Plant Sci. 9, 1876. https://doi.org/10.3389/fpls.2018.01876 (2018).

39. Hall, T. A. BioEdit: a user-friendly biological sequence alignment editor and analysis program for Windows 95/98/NT. Nucleic Acids Sumo. Ser. 41, 95-98. https://doi.org/10.1021/bk-1999-0734.ch008 (1999).

40. Thompson, J. D., Higgins, D. G. \& Gibson, T. J. CLUSTAL W: improving the sensitivity of progressive multiple sequence alignment through sequence weighting, position-specific gap penalties and weight matrix choice. Nucleic Acids Res. 22, 4673-4680. https://doi.org/10.1093/nar/22.22.4673 (1994).

41. Simmons, M. P. \& Ochoterena, H. Gaps as characters in sequence-based $\begin{array}{lllll}\text { phylogenetic analyses. Syst. } & \text { Biol. 49, 369-381. }\end{array}$ https://doi.org/10.1080/10635159950173889 (2000).

42. Kumar, S., Stecher, G. \& Tamura, K. MEGA7: molecular evolutionary genetics analysis version 7.0 for bigger datasets. Mol. Biol. Evol. 33, 1870-1874. https://doi.org/10.1093/molbev/msw054 (2016).

43. Clement, M., Posada, D. \& Crandall, K. A. TCS: a computer program to estimate gene genealogies. Mol. Ecol. 9, 1657-1659. https://doi.org/10.1046/j.1365-294x.2000.01020.x (2000).

44. Librado, P. \& Rozas, J. DnaSP v5: a software for comprehensive analysis of DNA polymorphism data. Bioinformatics 25, 1451-1452. https://doi.org/10.1093/bioinformatics/btp187 (2009).

45. Pons, O. \& Petit, R. J. Measwring and testing genetic differentiation with ordered versus unordered alleles. Genetics 144, 1237-1245. https://doi.org/doi:10.1016/S1050-3862(96)00162-3 (1996). 
46. Excoffier, L. \& Lischer, H. E. Arlequin suite ver 3.5: a new series of programs to perform population genetics analyses under Linux and Windows. Ecol. Resour. 10, 564-567. https://doi.org/10.1111/j.1755-0998.2010.02847.x (2010).

47. Rogers, A. R. \& Harpending, H. Population growth makes waves in the distribution of pairwise genetic differences. Mol. Biol. Evol. 9, 552-569. (1992).

48. Wolfe, K. H., Li, W. H. \& Sharp, P. M. Rates of nucleotide substitution vary greatly among plant mitochondrial, chloroplast, and nuclear DNAs. Proc. N. Acad. of Sci. USA 84, 9054-9058. https://doi.org/10.1073/pnas.84.24.9054 (1987).

49. Wang, Z. et al. Phylogeography study of the Siberian apricot (Prunus sibirica L.) in Northern China assessed by chloroplast microsatellite and DNA makers. Front. Plant Sci. 8, 1989. https://doi.org/10.3389/fpls.2017.01989 (2017).

50. Chin, S. W., Shaw, J., Haberle, R., Wen, J. \& Potter, D. Diversification of almonds, peaches, plums and cherries-Molecular systematics and biogeographic history of Prunus (Rosaceae). Mol. Phylogenet. Evol. 76, 34-48. https://doi.org/10.1016/j.ympev.2014.02.024 (2014).

51. Drummond, A. J., Suchard, M. A., Xie, D. \& Rambaut, A. Bayesian phylogenetics with BEAUti and the BEAST 1.7. Mol. Biol. Evol. 29, 1969-1973. https://doi.org/10.1093/molbev/mss075 (2012).

52. Li, M., Zhao, Z. \& Miao, X. J. Genetic variability of wild apricot (Prunus armeniaca L.) populations in the Ili Valley as revealed by ISSR markers. Genet. Resour. Crop Evol. 60, 2293-2302. https://doi.org/10.1007/s10722-013-9996-x (2013).

53. Li, M., Hu, X., Miao, X. J., Xu, Z. \& Zhao, Z. Genetic diversity analysis of wild apricot (Prunus armeniaca) populations in the lli Valley as revealed by SRAP markers. Acta Hortic. Sin. 43, 1980-1988. https://doi.org/10.16420/j.issn.0513-353x.2016-0156 (2016).

54. Hu, X., Zheng, P., Ni, B., Miao, X. \& Li, M. Population genetic diversity and structure analysis of wild apricot (Prunus armeniaca L.) revealed by SSR markers in the Tien-Shan mountains of China. Pak. J. Bot. 50, 609-615. (2018).

55. Decroocq, S. et al. New insights into the history of domesticated and wild apricots and its contribution to Plum pox virus resistance. Mol. Ecol. 25, 4712-4729. https://doi.org/10.1111/mec.13772 (2016).

56. Liu, S. et al. The complex evolutionary history of apricots: species divergence, gene flow and multiple domestication events. Mol. Ecol. Notes 28, 5299-5314. https://doi.org/doi.org/10.1111/mec.15296 (2019).

57. Posada, D. \& Crandall, K. A. Intraspecific gene genealogies: trees grafting into $\begin{array}{lllll}\text { networks. Trends Ecol. } & \text { Evol. } & \text { 16, } & \text { 37-45. }\end{array}$ https://doi.org/10.1016/S0169-5347(00)02026-7 (2001).

58. Boulnois, L. Silk road: monks, warriors \& merchants on the Silk Road 115-165 (WW Norton \& Co Inc, 2004)

59. Zhao, C., Wang, C. B., Ma, X. G., Liang, Q. L. \& He, X. J. Phylogeographic analysis of a temperate-deciduous forest restricted plant (Bupleurum 
longiradiatum Turcz.) reveals two refuge areas in China with subsequent refugial isolation promoting speciation. Mol. Phylogen. Evol. 68, 628-643. https://doi.org/10.1016/j.ympev.2013.04.007 (2013).

60. Ebersbach, J., Schnitzler, J., Favre, A. \& Muellner-Riehl, A. N. Evolutionary radiations in the species-rich mountain genus Saxifraga L. BMC Evol. Biol. 17. https://doi.org/10.1186/s12862-017-0967-2 (2017).

61. Favre, A. et al. The role of the uplift of the Qinghai-Tibetan Plateau for the evolution of Tibetan biotas. Biol. Rev. 90, 236-253. (2015). https://doi.org/10.1111/brv.12107

\section{Acknowledgments}

We are grateful to K.L. for the useful discussions and insightful comments, L.Q.L., Q.P.Z., W.Q.Z. and G.Q.F. for the assistance in collecting samples.

\section{Author contribution}

W.W.L., and K.L. conceived the study. L.Q.L., Q.P.Z., W.Q.Z. and G.Q.F. contributed to the sampling. W-WL and Adam collected and analyzed the data. W.W.L. and K.L. wrote the manuscript. All authors read and approved the final manuscript.

\section{Funding}

This work was supported by the National Key Research and Development Program (grant number 2016YFC0501504), the Xinjiang Uygur Autonomous Region Horticulture Key Discipline Fund (grant number 2016-10758-3), the Natural Science Foundation of Xinjiang Uygur Autonomous Region and the Xinjiang Agricultural University Crop science postdoctoral research station. The authors would like to thank the different research institutions, scientists, and breeders involved in this work and the company American Journal Experts (AJE) for providing English editorial assistance.

\section{Competing interests}

The authors declare that the research was conducted in the absence of any commercial or financial relationships that could be construed as a potential conflict of interest. 


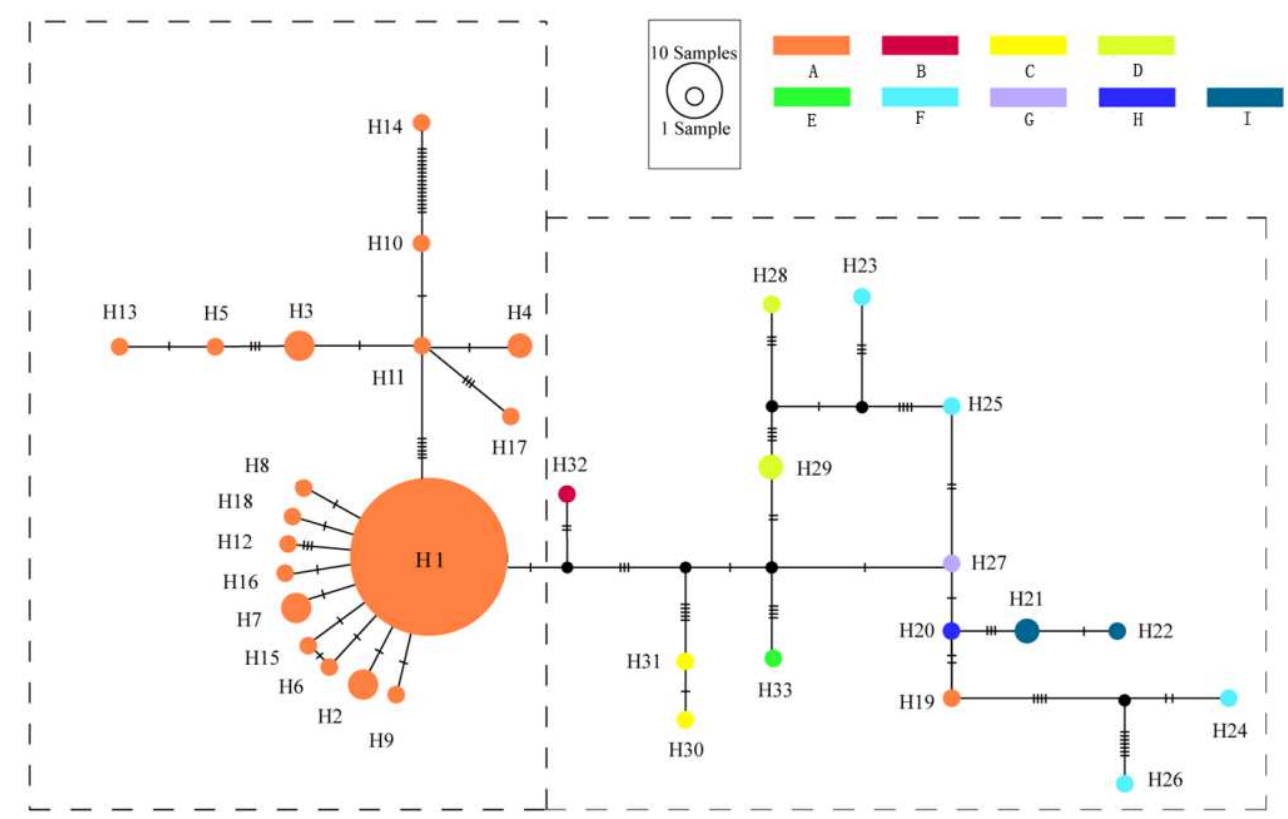

Figure 1. The haplotype network generated from the haplotypes of $P$. armeniaca and related species based on cpDNA dataset. The small black circles shown an intermediate haplotype not detected in this study. A, P. armeniaca; B, P. zhengheensis; C, P. davidiana; D, P. sibirica; E, P. dasycarpa; F, P. limeixing; G, P. mandshurica; H, P. mume; I, P. brigantina. 


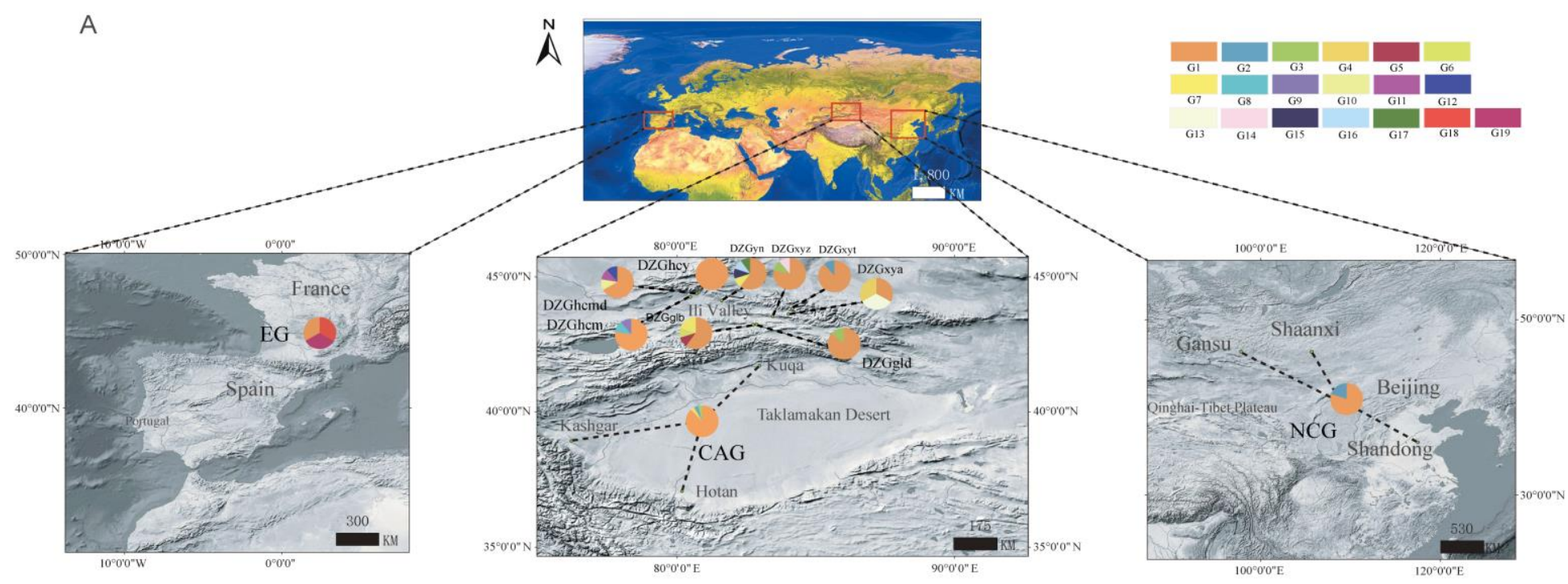

B

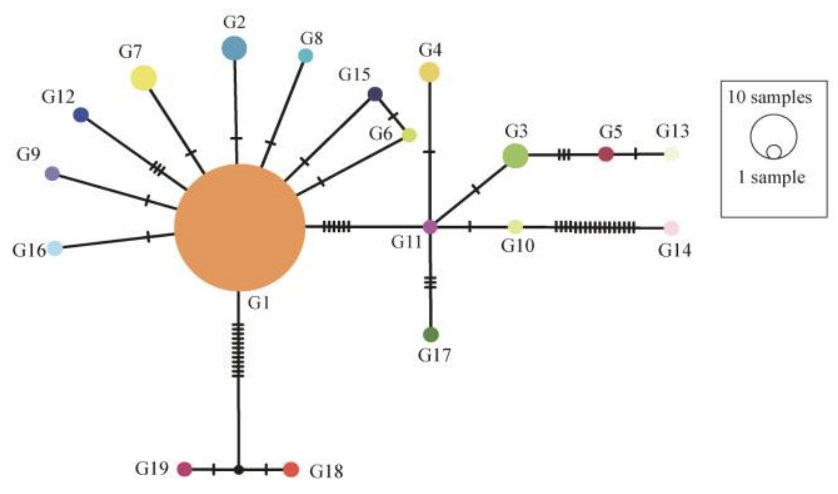

573 Figure 2. Geographic location and haplogroup distribution patterns of the 12 574 populations of $P$. armeniaca based on cpDNA dataset. (A) Geographic distribution of 575 haplotyoes of $P$. armeniaca; Pie chart size corresponds to the sample size of each 576 population. (B) The haplotype network generated from the haplotyoes of $P$. armeniaca. 577 The haplotype network generated from the 19 haplotypes of $P$. armeniaca. The small 578 black circles shown an intermediate haplotype not detected in this study. 

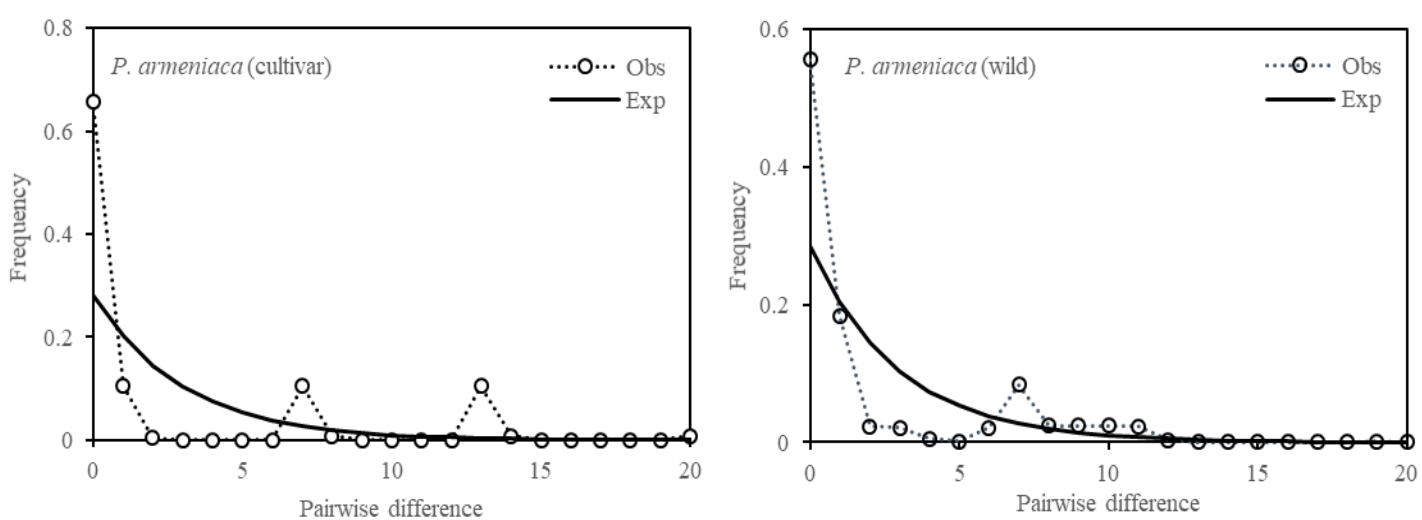

580

581

582

583

584

585

586

587

588

589

590

591

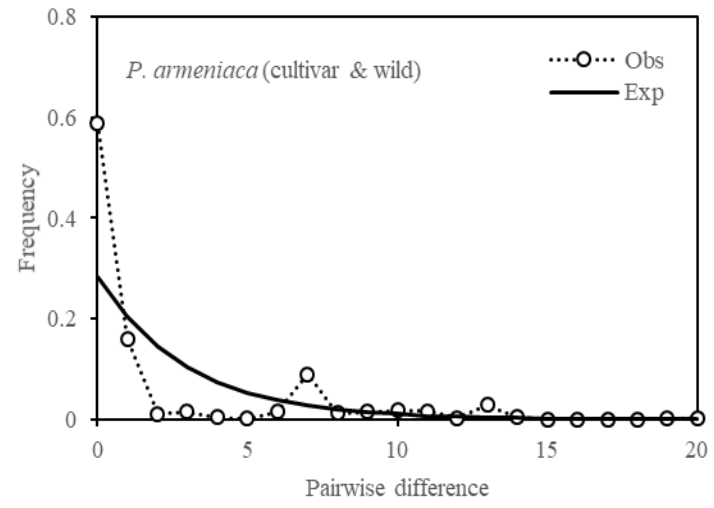

Figure 3. Mismatch distribution analysis of $P$. armeniaca based on overall gene pool of cpDNA dataset. 

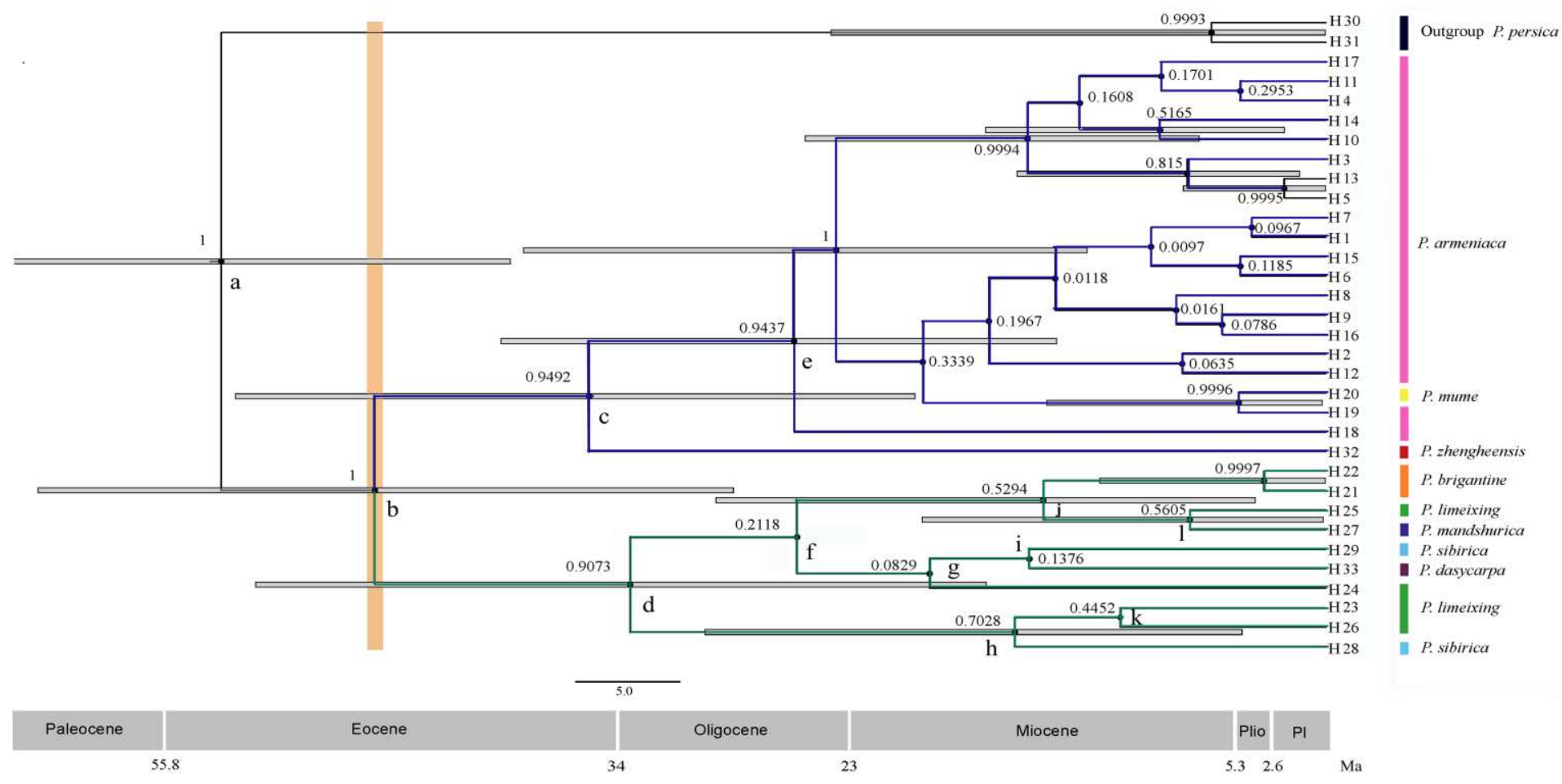

592 Figure 4. Bayesian phylogenetic tree based on cpDNA dataset. Gray bars represent 593 95\% highest posterior density intervals. Plio, Pliocene; Pl, Pleistocene; numbers 594 above the branches indicate Bayesian posterior probabilities. 


\begin{tabular}{|c|c|c|c|c|c|}
\hline Population & Origin/location & Type & $\begin{array}{c}\text { Latitude } \\
\left(\mathbf{N}^{\circ}\right)\end{array}$ & $\begin{array}{c}\text { Longitude } \\
\left(\mathbf{E}^{\circ}\right)\end{array}$ & $\begin{array}{l}\text { Altitude } \\
\text { (m) }\end{array}$ \\
\hline \multicolumn{6}{|l|}{ P. armeniaca } \\
\hline DZGhomd & Huocheng,Xinjiang & $\mathrm{W}$ & 44.43 & 80.79 & 1187.6 \\
\hline DZGhcy & Huocheng,Xinjiang & $\mathrm{W}$ & 44.44 & 80.79 & 1245.7 \\
\hline DZGhcm & Huocheng,Xinjiang & $\mathrm{W}$ & 44.40 & 80.71 & 1244.1 \\
\hline DZGyn & Yining,Xinjiang & W & 44.12 & 81.62 & 1983.6 \\
\hline DZGglb & Gongliu,Xinjiang & $\mathrm{W}$ & 43.25 & 82.86 & 1371.5 \\
\hline DZGgld & Gongliu,Xiniiang & $\mathrm{W}$ & 43.23 & 82.75 & 1269.4 \\
\hline DZGxyt & Xinyuan,Xinjiang & $\mathrm{W}$ & 43.54 & 83.44 & 1138.8 \\
\hline DZGxya & Xinyuan,Xiniiang & $\mathrm{W}$ & 43.50 & 83.70 & 1275.3 \\
\hline DZGxyz & Xinyuan,Xiniiang & $\mathrm{W}$ & 43.38 & 83.61 & 1374.1 \\
\hline $\mathrm{CAG}$ & Luntai,Xinjiang & $\mathrm{C}$ & 41.78 & 84.23 & 972.0 \\
\hline $\mathrm{NCG}$ & Luntai,Xinjiang & $\mathrm{C}$ & 41.78 & 84.23 & 972.0 \\
\hline EG & Xiongyue,Liaoning & $\mathrm{C}$ & 40.17 & 122.16 & 20.4 \\
\hline \multicolumn{6}{|l|}{ P. sibirica } \\
\hline NAG & Xiongyue,Liaoning & $\mathrm{W}$ & 40.17 & 122.16 & 20.4 \\
\hline \multicolumn{6}{|c|}{ P. mandshurica } \\
\hline LX & Xiongyue,Liaoning & $\mathrm{C}$ & 40.17 & 122.16 & 20.4 \\
\hline \multicolumn{6}{|l|}{ P. dasvcarpa } \\
\hline $\mathrm{ZX}$ & Luntai,Xinjiang & $\mathrm{C}$ & 41.78 & 84.23 & 972.0 \\
\hline \multicolumn{6}{|l|}{ P. mume } \\
\hline ECG & Xiongyue,Liaoning & $\mathrm{C}$ & 40.17 & 122.16 & 20.4 \\
\hline \multicolumn{6}{|c|}{ P. zhengheensis } \\
\hline ZHX & Xiongyue,Liaoning & $\mathrm{C}$ & 40.17 & 122.16 & 20.4 \\
\hline \multicolumn{6}{|l|}{ P. limeixing } \\
\hline LMX & Xiongyue,Liaoning & $\mathrm{C}$ & 40.17 & 122.16 & 20.4 \\
\hline \multicolumn{6}{|l|}{ P. brigantina } \\
\hline FGX & Xiongyue,Liaoning & $\mathrm{C}$ & 40.17 & 122.16 & 20.4 \\
\hline \multicolumn{6}{|l|}{ P. davidiana } \\
\hline $\mathrm{T}$ & Luntai, Xinjiang & $\mathrm{O}$ & 41.78 & 84.23 & 972.0 \\
\hline
\end{tabular}

Table 1. Population code, sampling location, coordinates, altitude and types of $P$. armeniaca and relative species. W, wild; C, cultivars; O, out group. 
598

\begin{tabular}{|c|c|c|c|c|c|c|c|c|}
\hline \multirow{2}{*}{ Population } & \multicolumn{4}{|l|}{ cpDNA } & \multicolumn{4}{|l|}{ ITS } \\
\hline & Haplotype composition & $\mathbf{N}$ & Hd & $\pi$ & Genotype composition & $\mathbf{N}$ & Hd & $\pi$ \\
\hline DZGhemd & $\mathrm{H} 1(6), \mathrm{H} 10(1), \mathrm{H} 11(1), \mathrm{H} 12(1)$ & 9 & 0.583 & 0.0016 & $\mathrm{~T} 2(2), \mathrm{T} 9(1), \mathrm{T} 14(1), \mathrm{T} 17(2), \mathrm{T} 19(1), \mathrm{T} 20(1), \mathrm{T} 21(1), \mathrm{T} 22(1)$ & 10 & 0.956 & 0.0082 \\
\hline DZGhcy & $\mathrm{H} 1(9)$ & 9 & 0.000 & 0.0000 & T3(2), T8(1), T9(3), T23(1), & 7 & 0.810 & 0.0067 \\
\hline DZGhcm & $\mathrm{H} 1(7), \mathrm{H} 8(1), \mathrm{H} 9(1)$ & 9 & 0.417 & 0.0002 & $\mathrm{~T} 2(1), \mathrm{T} 3(4), \mathrm{T} 8(1), \mathrm{T} 9(1), \mathrm{T} 18(1)$ & 8 & 0.786 & 0.0000 \\
\hline DZGyn & $\mathrm{H} 1(6), \mathrm{H} 7(1), \mathrm{H} 15(1), \mathrm{H} 16(1), \mathrm{H} 17(1)$ & 10 & 0.667 & 0.0011 & $\mathrm{~T} 1(1), \mathrm{T} 3(2), \mathrm{T} 8(2), \mathrm{T} 9(1), \mathrm{T} 14(2), \mathrm{T} 30(1)$ & 9 & 0.917 & 0.0087 \\
\hline DZGglb & $\mathrm{H} 1(6), \mathrm{H} 5(1), \mathrm{H} 6(1), \mathrm{H} 7(2)$ & 10 & 0.644 & 0.0012 & $\mathrm{~T} 2(1), \mathrm{T} 3(3), \mathrm{T} 8(2), \mathrm{T} 13(1), \mathrm{T} 14(1), \mathrm{T} 15(1)$ & 9 & 0.889 & 0.0043 \\
\hline DZGgld & $\mathrm{H} 1(6), \mathrm{H} 3(1)$ & 7 & 0.286 & 0.0010 & $\mathrm{~T} 3(4), \mathrm{T} 8(1), \mathrm{T} 16(1), \mathrm{T} 17(1)$ & 7 & 0.714 & 0.0027 \\
\hline DZGxyt & $\mathrm{H} 1(8), \mathrm{H} 2(1)$ & 9 & 0.222 & 0.0001 & $\mathrm{~T} 3(4), \mathrm{T} 8(2), \mathrm{T} 9(2), \mathrm{T} 12(1), \mathrm{T} 25(1)$ & 10 & 0.822 & 0.0032 \\
\hline DZGxya & $\mathrm{H} 1(1), \mathrm{H} 4(1), \mathrm{H} 13(1)$ & 3 & 1.000 & 0.0039 & $\mathrm{~T} 2(2), \mathrm{T} 24(1)$ & 3 & 0.667 & 0.0988 \\
\hline DZGxyz & $\mathrm{H} 1(7), \mathrm{H} 3(1), \mathrm{H} 14(1)$ & 9 & 0.417 & 0.0031 & T2(2), T3(2), T26(1), T27(1),T28(1), T29(2) & 9 & 0.917 & 0.0057 \\
\hline Within population & & 75 & 0.444 & 0.0013 & & 72 & 0.878 & 0.0055 \\
\hline CAG & $\mathrm{H} 1(21), \mathrm{H} 2(1), \mathrm{H} 3(1), \mathrm{H} 4(1)$ & 24 & 0.239 & 0.0006 & $\begin{array}{l}\mathrm{T} 1(5), \mathrm{T} 2(11), \mathrm{T} 3(8), \mathrm{T} 4(1), \mathrm{T} 5(1), \mathrm{T} 6(1), \mathrm{T} 7(1), \mathrm{T} 8(1), \mathrm{T} 9(1), \\
\mathrm{T} 10(1), \mathrm{T} 11(2), \mathrm{T} 12(1)\end{array}$ & 34 & 0.832 & 0.0053 \\
\hline NCG & $\mathrm{H} 1(4), \mathrm{H} 2(1)$ & 5 & 0.400 & 0.0002 & $\mathrm{~T} 1(1), \mathrm{T} 3(5), \mathrm{T} 9(2), \mathrm{T} 48(1), \mathrm{T} 49(1), \mathrm{T} 50(2)$ & 12 & 0.818 & 0.0047 \\
\hline EG & H1(1), H18(1), H19(1) & 3 & 1.000 & 0.0045 & $\mathrm{~T} 2(1), \mathrm{T} 3(4), \mathrm{T} 42(1)$ & 6 & 0.600 & 0.0053 \\
\hline Within population & & 32 & 0.343 & 0.0012 & & 52 & 0.833 & 0.0052 \\
\hline Among population & & 107 & 0.548 & 0.0019 & & 12 & 0.865 & 0.0054 \\
\hline NAG & $\mathrm{H} 28(1), \mathrm{H} 29(2)$ & 3 & 0.667 & 0.0023 & $\begin{array}{l}\text { T2(1), T3(6), T8(1), T9(1), T12(1), T25(1), T44(1), T45(1), } \\
\text { T46(1), T47(1) }\end{array}$ & 15 & 0.857 & 0.0104 \\
\hline $\mathrm{LX}$ & $\mathrm{H} 27(1)$ & 1 & 0.000 & 0.0000 & $\mathrm{~T} 3(4), \mathrm{T} 9(1)$ & 5 & 0.400 & 0.0014 \\
\hline $\mathrm{ZX}$ & $\mathrm{H} 33(1)$ & 1 & 0.000 & 0.0000 & $\mathrm{~T} 2(2), \mathrm{T} 55(1), \mathrm{T} 56(2), \mathrm{T} 57(2)$ & 7 & 0.857 & 0.0229 \\
\hline ECG & $\mathrm{H} 20(1)$ & 1 & 0.000 & 0.0000 & $\begin{array}{l}\text { T11(1), T31(1), T32(1), T33(1), T34(1), T35(1), T36(1), } \\
\text { T37(1), T38(1), T39(1), T40(1), T41(1) }\end{array}$ & 12 & 1.000 & 0.017 \\
\hline ZHX & $\mathrm{H} 32(1)$ & 1 & 0.000 & 0.0000 & T52(1), T53(1), T54(1) & 3 & 1.000 & 0.0047 \\
\hline LMX & $\mathrm{H} 23(1), \mathrm{H} 24(1), \mathrm{H} 25(1), \mathrm{H} 26(1)$ & 4 & 1.000 & 0.0051 & $\mathrm{~T} 3(3), \mathrm{T} 43(1)$ & 4 & 0.500 & 0.0170 \\
\hline FGX & $\mathrm{H} 21(2), \mathrm{H} 22(1)$ & 3 & 0.667 & 0.0003 & & & & \\
\hline
\end{tabular}


\begin{tabular}{l|l}
$\mathrm{T}$ & $\mathrm{H} 30(1), \mathrm{H} 31(1)$ \\
\hline
\end{tabular}

\begin{tabular}{l|l|l|l}
2 & 1.000 & 0.0005 & T51(1)
\end{tabular}

\begin{tabular}{l|l|l|}
1 & 0.000 & 0.0000 \\
\hline
\end{tabular}

599 Table 2. Sample information and summary of haplotype/genotype distribution, genetic diversity for each population. N, sample size; $H d$,

600 haplotype/genotype diversity; $\pi$, nucleotide diversity.

601 


\begin{tabular}{|l|l|l|l|l|l|l|l|l|}
\hline \multirow{2}{*}{ Populations } & \multicolumn{2}{|l|}{ cpDNA } & \multicolumn{2}{l|}{ ITS } \\
\cline { 2 - 9 } & $\boldsymbol{H}_{\boldsymbol{S}}$ & $\boldsymbol{H}_{\boldsymbol{T}}$ & $\boldsymbol{G}_{\boldsymbol{S} \boldsymbol{T}}$ & $\boldsymbol{N}_{\boldsymbol{S} \boldsymbol{T}}$ & $\boldsymbol{H}_{\boldsymbol{S}}$ & $\boldsymbol{H}_{\boldsymbol{T}}$ & $\boldsymbol{G}_{\boldsymbol{S} \boldsymbol{T}}$ & $\boldsymbol{N}_{\boldsymbol{S} \boldsymbol{T}}$ \\
\hline P. armeniaca (Cultivated \& Wild) & 0.490 & 0.499 & 0.020 & $0.227^{*}$ & 0.794 & 0.876 & 0.094 & $0.126^{*}$ \\
\hline
\end{tabular}

Table 3. Estimates of average gene diversity within populations $\left(H_{S}\right)$, total gene diversity $\left(H_{T}\right)$, interpopulation differentiation $\left(G_{S T}\right)$ and number of substitution types $\left(N_{S T}\right)$ for cpDNA haplotypes and ITS genotypes of $P$. armeniaca. Ns, not significant; $*, P<0.05$.

\begin{tabular}{|l|l|l|l|l|l|l|l|l|l|l|}
\hline \multirow{2}{*}{ Source of variation } & \multicolumn{9}{|l|}{ cpDNA } & \multicolumn{10}{l|}{ ITS } \\
\cline { 2 - 13 } & $\boldsymbol{d} \boldsymbol{f}$ & $\boldsymbol{S S}$ & $\boldsymbol{V C}$ & $\boldsymbol{P V}(\boldsymbol{\%})$ & $\boldsymbol{F}_{\boldsymbol{S} \boldsymbol{T}}$ & $\boldsymbol{d} \boldsymbol{f}$ & $\boldsymbol{S S}$ & $\boldsymbol{V} \boldsymbol{P}$ & $\boldsymbol{P} \boldsymbol{( \% )}$ & $\boldsymbol{F}_{\boldsymbol{S} \boldsymbol{T}}$ \\
\hline Among populations & 11 & 31.699 & 0.209 & 16.28 & & 11 & 23.777 & 0.068 & 4.38 & \\
\hline Within populations & 95 & 102.086 & 1.075 & 83.72 & & 112 & 166.844 & 1.490 & 95.62 & \\
\hline Total & 106 & 133.785 & 1.284 & & $0.1628^{*}$ & 123 & 190.621 & 1.558 & & $0.0297^{*}$ \\
\hline
\end{tabular}

Table 4. Analyses of molecular variance (AMOVA) of cpDNA haplotypes and ITS genotypes for populations of $P$. armeniaca. $d f$, degrees of freedom; $S S$, sum of squares; $V C$, variance components; $P V$, percentage of variation; $F_{S T}$, fixation index; $* P<0.001$.

\begin{tabular}{|l|l|l|l|l|l|l|l|l|l|}
\hline \multirow{2}{*}{ Populations } & \multicolumn{2}{|l|}{ Tajima's $\boldsymbol{D}$-test } & \multicolumn{2}{l|}{ Fu's $\boldsymbol{F}$-test } & \multicolumn{3}{l|}{ Mismatch distribution } \\
\cline { 3 - 10 } & $\boldsymbol{D}$ & $\boldsymbol{P}$ & $\boldsymbol{F}$ S & $\boldsymbol{P}$ & SSD & $\boldsymbol{P}$ & HRI & $\boldsymbol{P}$ \\
\hline \multirow{3}{*}{ cpDNA } & Overall & -2.417 & $0.000^{*}$ & -6.350 & $0.025^{*}$ & 0.232 & 0.150 & 0.218 & 0.600 \\
\cline { 2 - 10 } & P. arminiaca (cultivated) & -1.933 & $0.003^{*}$ & 1.289 & 0.772 & 0.038 & 0.250 & 0.356 & 0.500 \\
\cline { 2 - 10 } & P. arminiaca (wild) & -2.272 & $0.001^{*}$ & -5.825 & $0.021^{*}$ & 0.037 & 0.070 & 0.179 & 0.880 \\
\hline \multirow{3}{*}{ ITS } & Overall & -1.193 & 0.106 & -8.587 & $0.010^{*}$ & 0.002 & 0.660 & 0.023 & 0.700 \\
\cline { 2 - 9 } & P. arminiaca (cultivated) & -1.420 & 0.155 & -4.951 & $0.024^{*}$ & 0.015 & 0.020 & 0.063 & 0.310 \\
\cline { 2 - 10 } & P. arminiaca (wild) & -0.966 & $0.041^{*}$ & -12.223 & $0.000^{*}$ & 0.002 & 0.810 & 0.017 & 0.880 \\
\hline
\end{tabular}

Table 5. Neutrality tests (Tajima's $D$ and Fu's $F_{S}$ ) and mismatch distribution analysis for the $P$. armeniaca based on the cpDNA and ITS dataset. $* P<0.05$. 


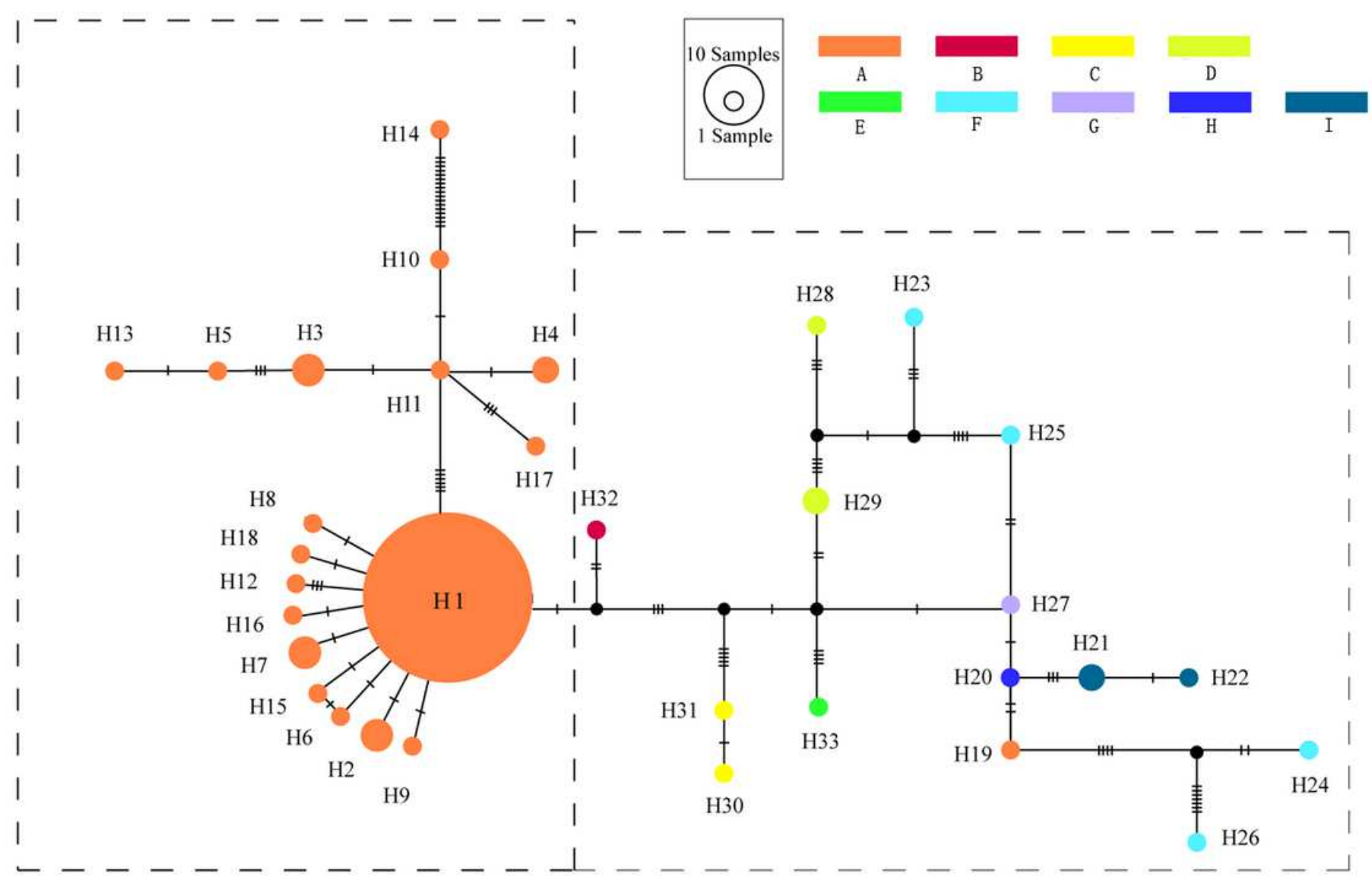

\section{Figure 1}

The haplotype network generated from the haploty $\mathrm{p}$ es of P. armeniaca and related species based on $\mathrm{cp}$ D NA dataset dataset. The small black circles shown an intermediate haplotype not detected in this study. A, P. armeniaca ; B, P. zhengheensis; C, P. davidiana; D, P. sibirica; E, P. dasycarpa; F, P. limeixing G, P. mandshurica H, P. mume; I, P. brigantina. 


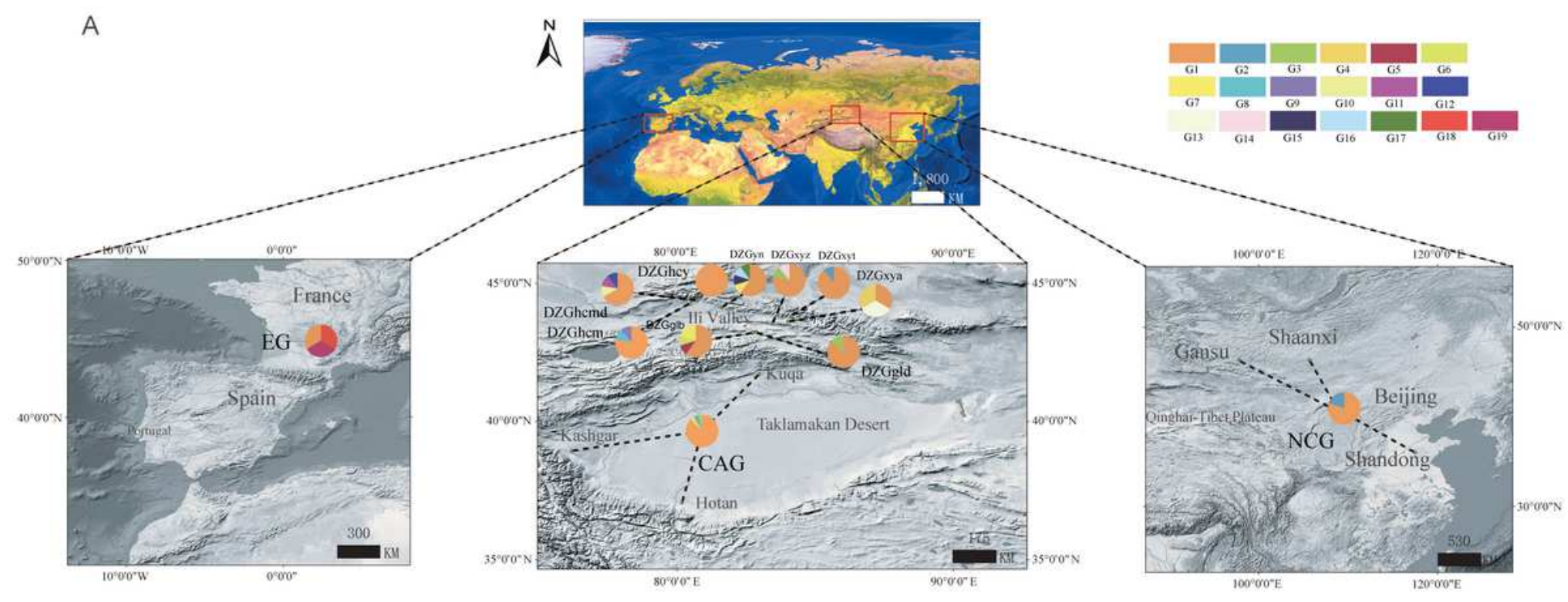

B

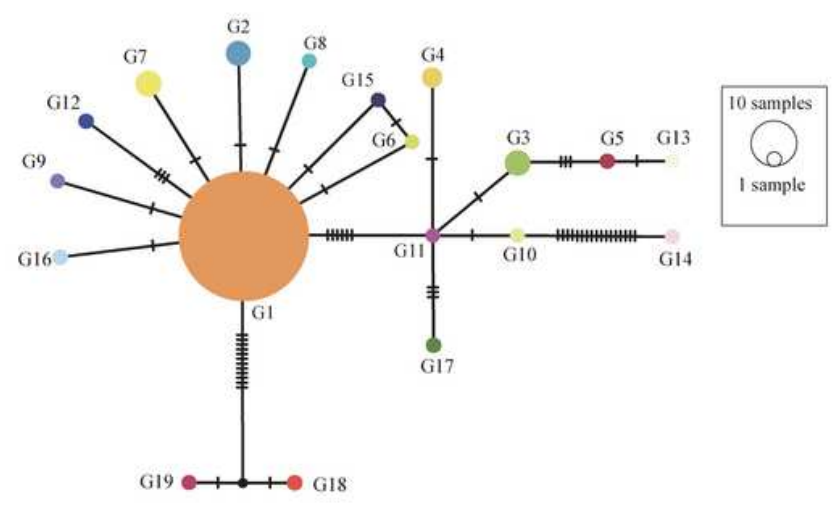

\section{Figure 2}

Geographic location and haplogroup distribution patterns of the 12 populations of P. armeniaca based on cpDNA dataset. (A) Geographic distribution of h aplotyoes of P. armeniaca ; Pie chart size correspond s to the sample size of each population. (B) Th e haplotype network generated from the haplotyoes of $P$. armeniaca. The haplotype network generated from the 19 haplotypes of P. armeniaca The small black circles shown an intermediate haplotype not detected in this study. Note: The designations employed and the presentation of the material on this map do not imply the expression of any opinion whatsoever on the part of Research Square concerning the legal status of any country, territory, city or area or of its authorities, or concerning the delimitation of its frontiers or boundaries. This map has been provided by the authors. 

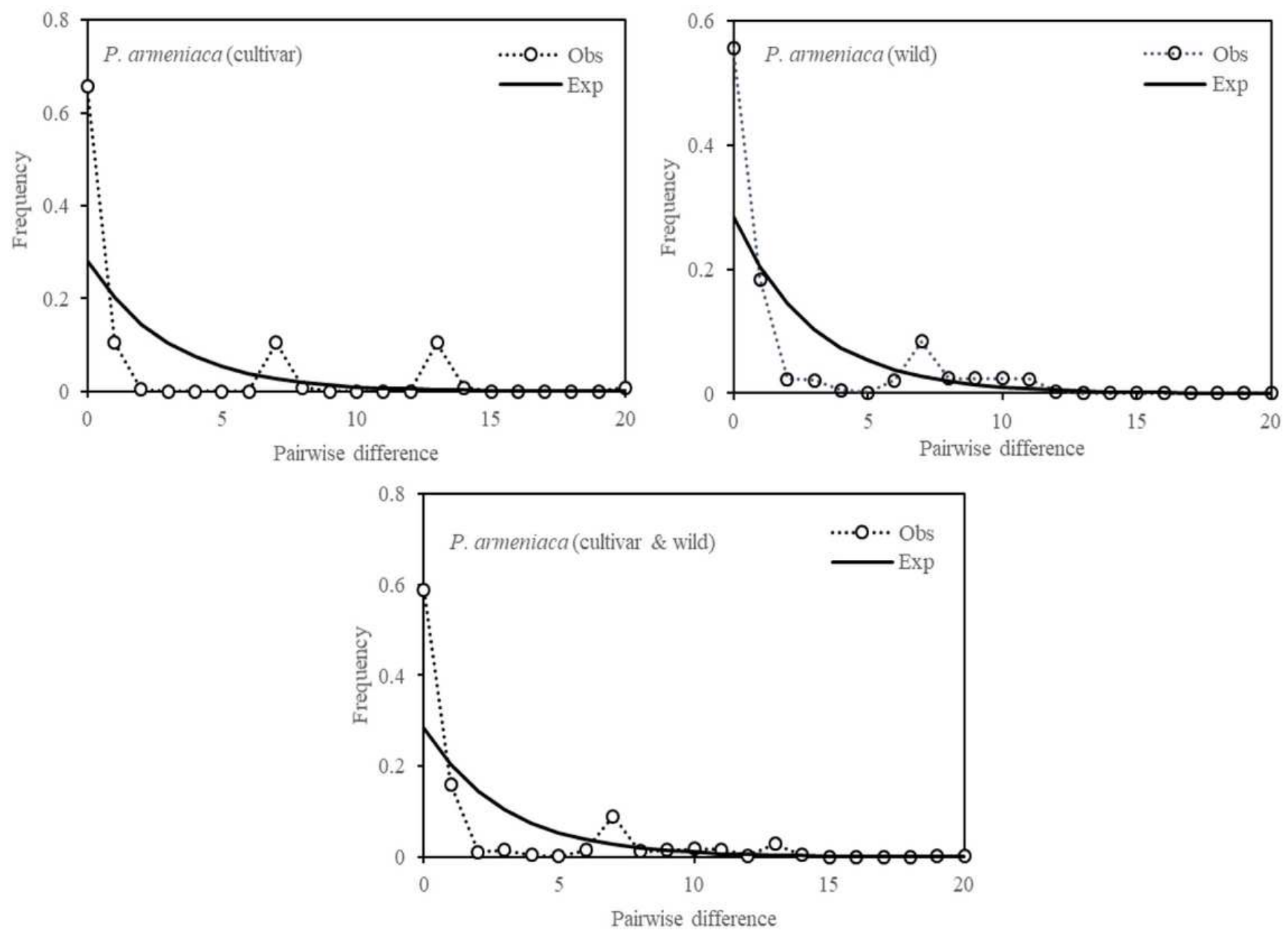

Figure 3

Mismatch di stribut ion analysis of $\mathrm{P}$ armeniaca based on overall gene pool of cpDNA dataset. 

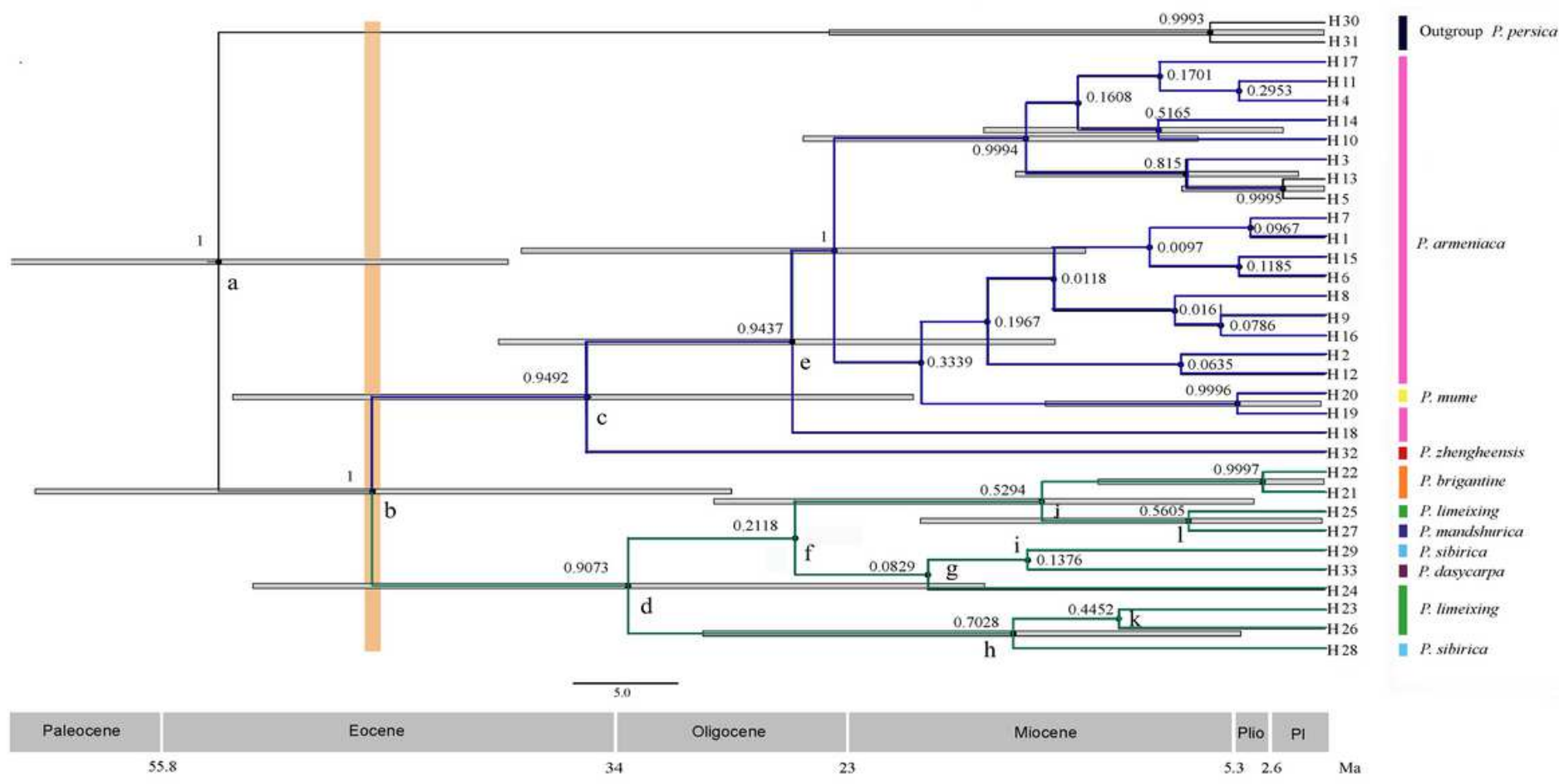

\section{Figure 4}

Bayesian phylogenetic tree based on cpDNA dataset. Gray bars re present $95 \%$ highest posterior density intervals. Pli o, Pliocene; PI, Pleistocene; numbers above the branches indicate Bayesian posterior probabilities.

\section{Supplementary Files}

This is a list of supplementary files associated with this preprint. Click to download.

- SupplementaryFigures.docx

- TablesS1.docx

- TablesS2.docx

- TablesS3.docx

- TableS4.xIsx

- TableS5.xIsx

- TableS6.xIsx

- TablesS7.docx 